\title{
Opportunities to Achieve a Sustainable Restaurant Business
}

\author{
Olga Mancheva-Ali \\ Vasil Levski National Military University, Veliko Tarnovo, Bulgaria \\ lliyan Lilov \\ Vasil Levski National Military University, Veliko Tarnovo, Bulgaria
}

\begin{abstract}
This report examines the place of restaurant business in the tourism system and its importance in the formation and realization of the tourist product. Due to its leading role in tourism, opportunities are being sought to apply new tools and methods to achieve sustainable development, including reducing its harmful impact on the environment and creating new, more favourable habits for consumers. There is a study of good practices in the world and their potential application in Bulgarian catering establishments as possible ways to achieve sustainable restaurants. In addition, a survey is conducted among potential users of restaurant services to determine their attitude and role in achieving sustainable results.
\end{abstract}

Keywords: sustainability, restaurant business, development JEL classification: M14, Z32

\section{Introduction}

Restaurant business is a major tourist activity, which is involved in the formation and realization of the tourist product as a package of tangible and intangible components designed to satisfy the needs, desires and expectations of tourists at a certain price (Kwok et al., 2013). As a subsystem of tourism, restaurant industry ensures satisfaction of the basic people's necessity of food (Mihaylov, 2014). The current regulatory frameworks in Bulgaria, and in particular the Tourism Act, in force as of 26.03.2013, amended and supplemented, SG 75 of 27 September 2016 (State Gazette of Bulgaria, 2016), defines the restaurant industry as the main tourist activity, which makes provision of tourist services in specific forms according to the type of the tourist site".

In parallel with satisfying the needs of tourists to have a meal out, some concomitant issues that are relevant to business in a more global context also arise (Kjaerheim et al., 1996). Restaurant industry is related to different sectors of the economy as it uses products from them to carry out its activities (Hwang et al., 2010). Many of these products are used in the production of culinary products, and this is one of the aspects that we need to follow. It is a common practice food to be ordered in restaurants, and that food is not fully consumed, so it becomes a waste material that has mostly no purpose except to be thrown together with inorganic products and materials. Many authors and non-governmental organizations are exploring the possibilities for changing the attitudes of tourists to achieve sustainable hotel industry (Revell, 2007). However, we think that the emphasis should be shifted to restaurant business, which in recent years has shown that it generates higher revenues than those of the hotel industry. We should also make another important point - as food consumption occurs not only in restaurants but also in our homes, the 
focus of this study is only on the first group and the opportunities for achieving sustainable development in restaurant industry.

Our study aims to gather information about the various ways to address the problem described so as to save resources and to use them in accordance with the principles of sustainable development. In order to improve the analysis of the topic, besides exploring the experience of the different countries, an online survey is conducted among restaurant customers and their attitudes towards participation in the process of achieving a sustainable restaurant business are analysed. This survey was conducted among Bulgarian service users.

\section{Literature review}

Importance of nutrition in the tourism system

Each business is bound by specific data about its consumption and success in the sector where it is realized. This is the case with the restaurant business, which has a leading position among the tourist services, as evidenced by data from the national statistics of Bulgaria (Diagram 1).

Figure 1

Average Cost per Type (Excluding Tourist Package) for Trips of Persons Aged over 15 until 2015, 2016 and 2017 for Bulgaria

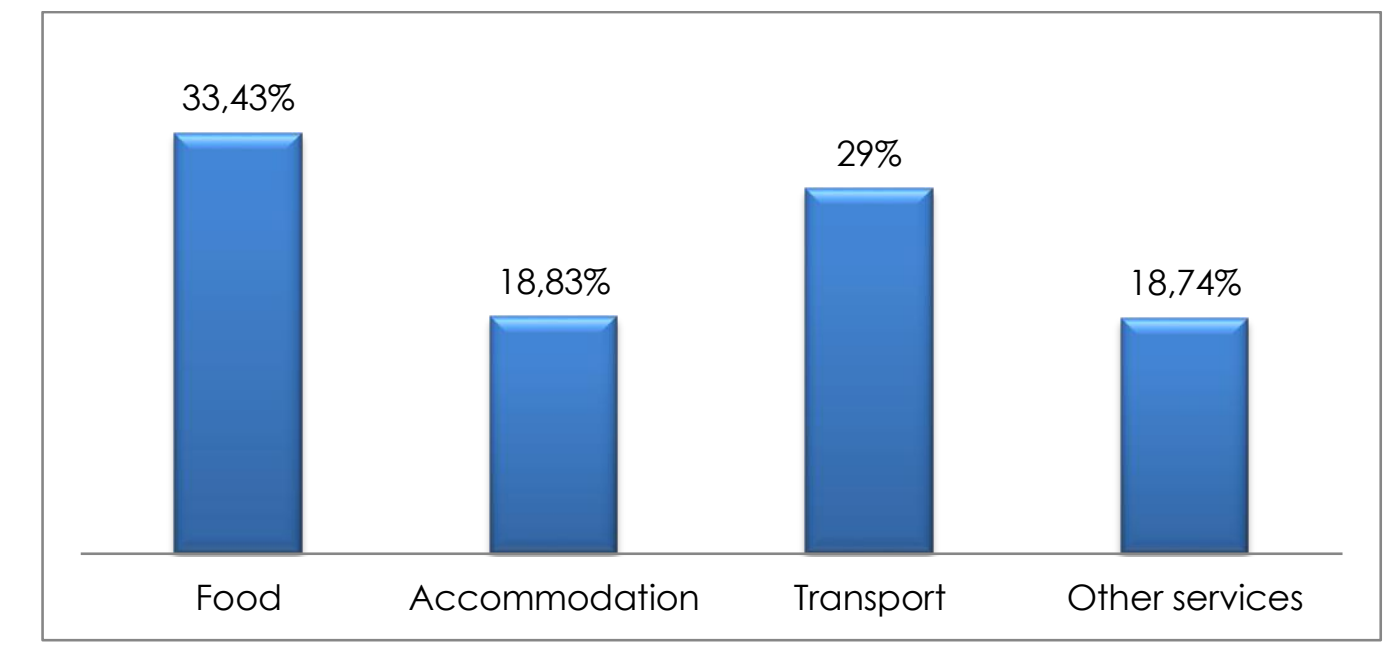

Source: Authors' illustration

The figures in the chart make it clear that tourists spend the most money on food, followed by transport, accommodation and other services. Data is average for the last three years for Bulgaria.

Another important thing to remember is that at the base of the restaurant industry there are three main activities that play the role of the main components (elements) of the restaurant business. They are presented in figure 1. 
Figure 2

Core Elements of Restaurant Business

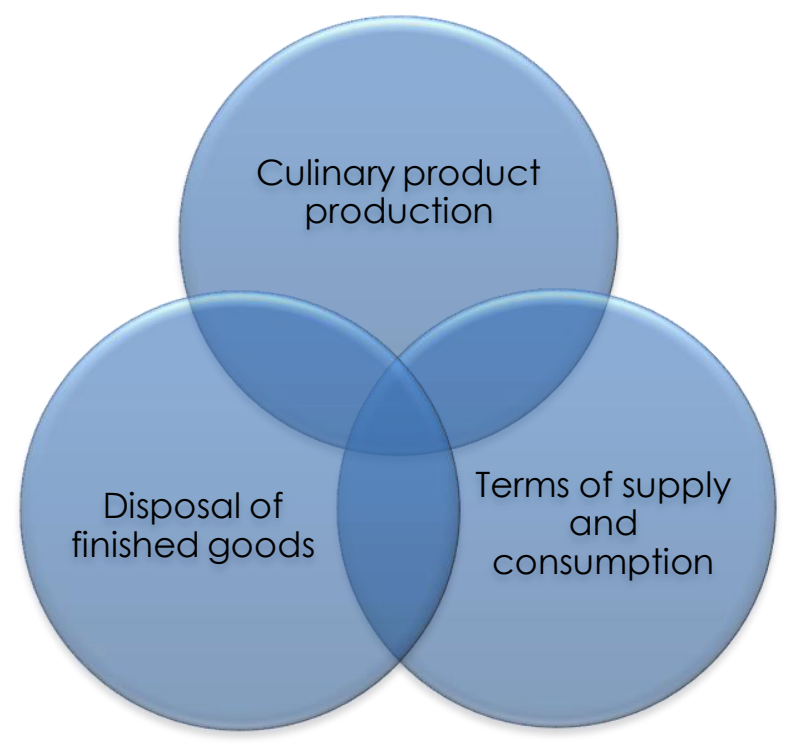

Source: Authors' illustration

There is a relationship between the elements of the figure. It makes them a common product that forms the essence of the restaurant business. Elements and their sustainable aspects are listed as the basis for selecting a topic, but for better justification it is necessary to clarify the concept of "Sustainable Tourism".

The theory of sustainable development is based on the idea of control and prevention of crises through material and technical progress, scientific and technological discoveries in economic, social, environmental and demographic aspects.

In recent years, the concept of sustainable development has become an innovative opportunity for business structures to choose new ways to achieve their goals to maintain their competitive advantages and to carry out balanced planning and use of resources.

In the Bulgarian Tourism Act, effective as of 26.03.2013, amended and supplemented, SG 75 of 27 September 2016 (State Gazette of Bulgaria, 2016), the following definition of "sustainable tourism" is given and it is that "Sustainable tourism is any form of development, device or tourist activity that preserves and protects the natural, cultural and social resources in the long term and contributes, in a positive and balanced way, to the economic development and prosperity of people living, working or residing in these territories.

\section{Opportunities for achieving sustainable development}

Some opportunities for development and concrete examples of sustainability of the three key elements of the restaurant business described in Figure 1 should be presented, namely:

- Production of culinary products - the following fact is worth mentioning: in 2015 in Bulgaria, the first culinary competition for sustainable cooking took place. It was organized by the Institute of Culinary Arts in Varna. The 
organizers define sustainable cooking as "preparing and storing the food without disturbing the basic principles of nature, preserving the beneficial substances and the taste qualities of the product (Culinary Arts Institute, 2015). In the race regulation, there is an indicator for successful cooking: the least amount of cooking waste. Both non-professional chefs, mostly students trained in the profession, as well as professional chefs, take part in the competition and the two groups compete in different categories. The competition has the important task of forming chefs' attitudes towards the future development of the profession. Some of the most famous chefs who work for the sustainable cooking cause are the Roca brothers. They share the motto "Food should not be a threat to sustainability but a source of sustainable development," and they implement their ideas in their restaurant El Celler de Can Roca (Girona, Spain). It has 3 Michelin stars and traditionally ranks in the A list of the prestigious World's 50 BestRestaurants 2017, which the British magazine Restaurant holds annually.

To the possibilities of achieving sustainable cooking, we should add the latest technological solutions in the preparation of culinary products such as low temperature cooking. This type of cooking is not new as an idea, as it is vacuum cooking, but the innovation is related to making accurate control over the cooking temperature. The advantages of the technology are both for the prepared meals (reducing product loss by $15-35 \%$, which depends on the ingredients) and reducing site costs by saving energy (20-28\%).

- Disposal of finished products - it is associated with achieving sustainable consumption, and one of the easiest and achievable things that consumers can do is to take the waste food home. This idea is successfully developed and implemented in Scotland, where the government supports the provision of free food boxes in restaurants. Within a year (2015) in 9 out of 10 restaurants waste food dropped by $40 \%$. It is believed that the accompanying information campaign on the importance of food waste on the environment is reflected, and 1/5 of the success is believed to be due to free food boxes. The project has been implemented in 100 restaurants so far and the aim is to include more 100 restaurants in the next stage. Another example in this direction is the restaurants in France where, as a result of the efforts to limit food waste, similar boxes are provided to customers. This is part of an initiative taken by the French government in 2013 to reduce food waste by $50 \%$ by 2025. The Scottish government, for its part, has set more modest goals, and they are to cut food waste by $33 \%$ by 2025 with the introduction of free food boxes.

We cannot help but mention that the issue has basically two main points and they are: users and chefs. A study found that a large number of chefs, especially in highclass restaurants, do not approve of the idea the food the cooked to be put in such a container (a food box). On the other hand, the popular name of these bags is "doggy bag", which seems to bother some consumers and makes them ashamed to take the food they have failed to consume on site. For this reason, it is suggested that these bags be called the "gourmet bag" following the example of Scotland, which has a positive effect on the consumers' attitudes. In this system of activities, organizations (NGOs, government-funded organizations as well as European funded) which have a particular mission and goals to achieve sustainability in the restaurant business.

- Terms of supply and consumption - it can be defined as the final outlook of a restaurant, in particular the achievement of sustainable (green) restaurants. In 
this direction, American restaurateurs as well as organizations specialized in working on establishing certification criteria for restaurants have good experience. It concerns the application of certain standards and obtaining a certificate for that. One of the most popular organizations is the Green Restaurant Association (n.d.), positioned in Boston, USA. The organization relies on 7 major certification points and they are: Water Efficiency, Waste Reduction and Recycling, Sustainable Durable Goods \& Building Materials, Sustainable Food, Energy, Reusables \& Environmentally Preferable Disposables, Chemical and Pollution Reduction.

In Europe a sustainable restaurant is recognized as a "green restaurant" for which it is characteristic to ensure green and environment-friendly environment but in urban conditions, rather than certification by specific indicators. As we have learned, European businesses have introduced successful practices in sustainability. However, at this stage, they are limited to a certain aspect of the restaurant business. There is an interesting ranking of "Top 12 Green Restaurants in Europe", which shows the attitude towards work in this direction.

In 2016, the Bulgarian magazine BACCHUS, in its categories for annual awards of famous restaurants, included a new category called: "Sustainable Concept". With this award, the magazine aims to encourage and distinguish those innovators who make efforts to follow the concepts of sustainable development: clean / local / seasonal / farm products; minimization of food waste and waste of resources; menus based on seasonal, balanced and healthy eating; contribution to the preservation of local products and traditions; user-friendly and environment-friendly cooking techniques (BACCHUS magazine, 2017).

An analysis of business experience shows that the foundations of sustainable food practices have been laid, but due to the specificities of different markets and customers, each region should develop its own approaches to achieve sustainability.

\section{Methodology}

\section{Analysis}

Because of the different aspects of the problem, the next stage of the survey covers consumer attitudes as participants in the process of accomplishing a sustainable restaurant business. There has been an online survey, conducted among Bulgarian consumers by using the Google survey platform for achieving this objective. Users are asked ten key questions, regarding their attitudes, with 6 of them directly addressing the sustainable restaurant business and two open-ended questions in the form of inquiries and comments.

\section{Data}

For the period 24.02-03.03.2018, 149 people were surveyed, 83.2\% of which were women and $16.8 \%$ were men.

The highest percentage of participants turned out to be those with master's degree $-46.3 \%$, followed by $23.1 \%$ with bachelor's degree, $21.8 \%$ with secondary education (including university students), $6.8 \%$ with $\mathrm{PhD}$ degree and $2 \%$ with professional bachelor's degree. Most of the surveyed are employed people $-70.3 \%$, followed by students $-16.2 \%, 7.4 \%$ with their own business and the lowest $\%$ of others (unemployed and on maternity leave). The target group of the survey consists of people over the age of 19, who use restaurant services.

The age structure of the surveyed is presented in Diagram 2. 
Figure 3

Age Structure of the Surveyed Participants

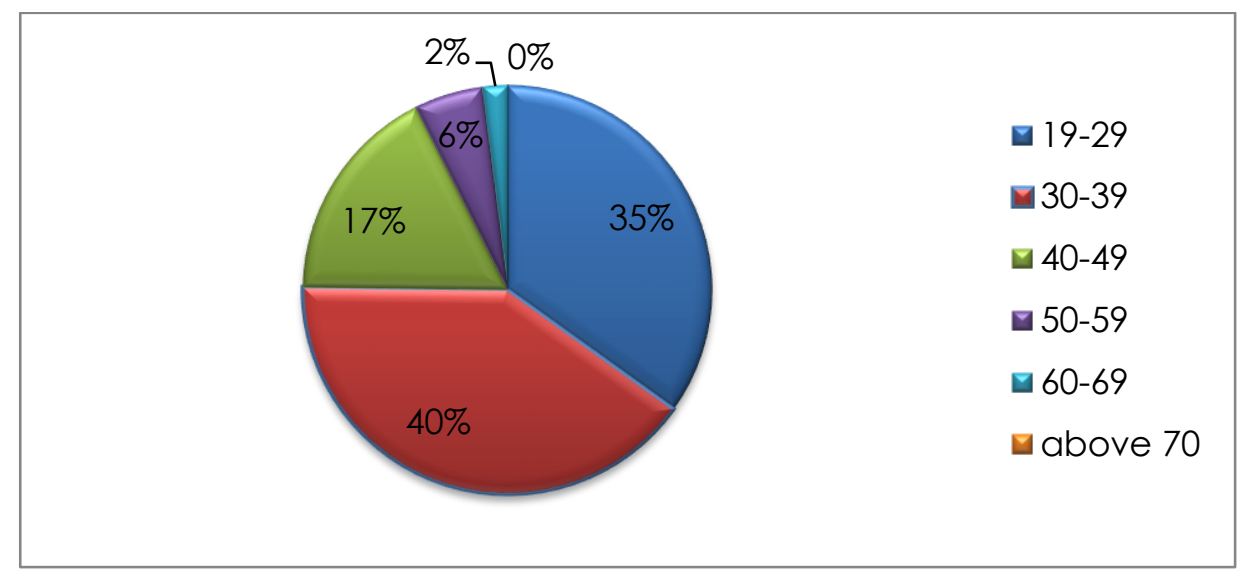

Source: Author's illustration

It is obvious that $98 \%$ of the surveyed are of working age, with the highest percentage being those aged 30-39 (40\%), followed by the groups: 19-29 (35\%), 4049 (17\%), 50-59 (6\%) and 60-62 (2\%). We do not have participants over the age of 70 .

\section{Results}

The survey results have a clear objective which is to analyse the consumer attitudes on the studied issues. As a starting point, it could be said that the survey participants are people who use restaurants services quite frequently, as $36.7 \%$ of them have responded that they visit a restaurant $1-2$ times a week, $26.5 \%$ of them do this once or twice a month. There is also a great number of people, who visit restaurants every day $-11.6 \%$ of the surveyed.

The following questions focus on the sustainable use and the role of the consumer. We should first outline the answers of the users, participating in the survey, of the question what they associate the idea of sustainable restaurant business with $-51.4 \%$ of them answer that this is a restaurant that saves on resources by using high technologies, $11.6 \%$ think it is a restaurant with a specific interior and exterior which is close to the nature, $6.8 \%$ define it as a profiled (green, bio) restaurant and the rest associate the sustainable restaurant with vegetarian and vegan food, with a modern restaurant, etc. There is also a high percentage of consumers - $23.3 \%$, who cannot accurately define the concept.

On the question "Are you ready to replace the traditional restaurant with a "sustainable one", if you know that you will improve the environment in which you live?" the participants with positive answers have the highest percentage $(43.5 \%)$ and $29.3 \%$ of them would replace the traditional restaurant for a sustainable one, but they still need time to figure out the idea.

Only $5.4 \%$ give a clear "no" response and $20.4 \%$ of the consumers cannot decide at this point.

After answering the general questions, the respondents also replied to specific ones, one of which is, "When you cannot eat all the food you have ordered in a restaurant, what do you do with it?" The results show that $18.4 \%$ of the consumers 
usually take the rest of their food for home, and $14.3 \%$ take it, only if the waiter offers them.

It turns out that $21.1 \%$ leave the table to be cleared and do not have the habit to ask for getting the food boxed up. The largest number of consumers (42.9\%) reply that if they are accompanied by friends, they prefer to share it with them.

In the survey, we also asked "Do you feel embarrassed when you want to take the rest of your food boxed up?" We got the following answers - $52.4 \%$ are not embarrassed at all, and they think that once they have paid for their food, they should take it home. It is rather surprising that $34 \%$ responded that they would have taken their food but preferred the waiter to offer it to them, $10.2 \%$ share their concern to take their food because they think this practice is not well-accepted by the waiters.

The next question is related to the food box. It turns out that it does not matter whether it is free or not. Positive answers have a little prevail, namely that if the box is free it will make consumers take their food.

As a key question, we can set the following one "Would you be more motivated than usual if you knew that by taking your food, you are helping reduce waste?". The answers can be seen in Diagram 3.

Figure 4

Answers to the Question: "Would You Be More Motivated than Usual if You Knew that by Taking Your Food, You Are Helping Reduce Waste?"

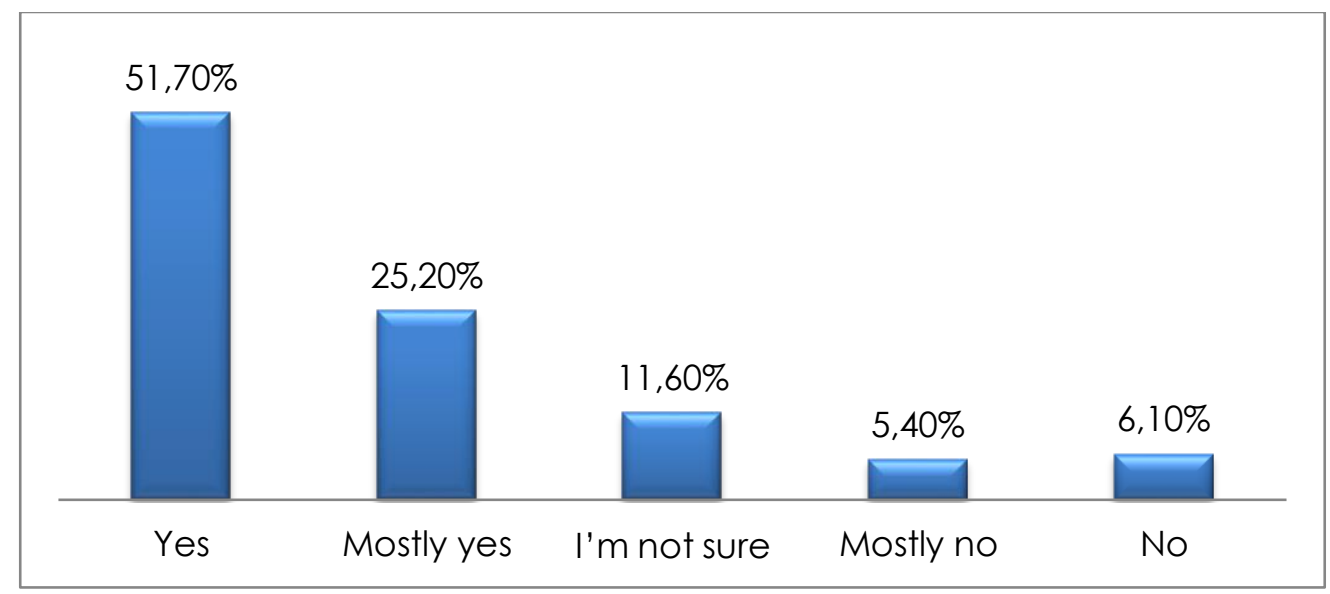

Source: Authors' illustration

We cannot miss the chance to share some of the comments, made by the respondents and these comments are associated with their desire to visit a restaurant with sustainable practices and to participate in the process of sustainability as well. Some consumers say they have visited a restaurant with established practices in this regard but it is not a place with an implemented complete system, which covers all aspects of the sustainable restaurant business.

\section{Discussion}

We can therefore draw several specific conclusions of the results obtained, as understanding and defining the concept of sustainability by the restaurant service consumers; the perception of implementing a change in the way of service consumption in restaurants; key role of the waiter, with regard to the decisions, made by the consumers; the price of the food box is irrelevant to the consumer's 
attitude; consumers' motivation to take the food left is much stronger if they know this helps improve the environment. We can conclude that Bulgarian consumers have the attitude to change the way in which restaurant services are consumed.

\section{Conclusion}

In this article a research about one of the aspects for achieving sustainable restaurant business is made. In its focus are customers of restaurant service and their eagerness of taking part in the process of achieving sustainable restaurant product. The questionnaire created by the authors has been spread among Bulgarian customers who demonstrated their attitude to the issue.

The sustainable restaurant business is a problem detected by American and East European authors. While studying the literature and tracking the researches lead on this issue, partial researche of certain aspects is found but very few of them represent a full vision. In Bulgaria such research has not been found and this gave extra motivation for conducting such empirical research.

As a consequent step, a wider one is to be conducted as well as analysis of usiness' attitude made. In result a model of achieving sustainable restaurant business has to be established which could be applicable in Bulgarian restaurants. As one of the biggest constraints is considered the number of respondents in the questionnaire together with their territorial disposition. The authors are planning a wider research to be made. It will be pointed to American and East European customers of restaurant services. The purpose is larger number of opinions to be gathered and consequently successful practices to be shared. They could be a good ground for the future model of a sustainable restaurant business.

\section{References}

1. BACCHUS magazine (2017), "Nominations for "Restaurant of the year" Bacchus, Acqua Panna \& San Pellegrino" for 2016", available at:

2. Culinary Arts Institute (2015), "The first culinary competition on sustainable cooking in Bulgaria!", available at: http://culinaryartseurope.com/bg/2015/12/04/purvosustezanie-po-ustoichivo-gotvene/ (08 July 2018)

3. Green Restaurant Association (n.d.), available at: http://www.dinegreen.com/greenmy-restaurant

https://www.bacchus.bg/novini/2017/02/22/2922754_nominaciite_za_restorant_na_g odinata_bakhus_acqua/ (08 July 2018)

4. Hwang, J., Zhao, J. (2010), "Factors influencing customer satisfaction or dissatisfaction in the restaurant business using AnswerTree methodology", Journal of Quality Assurance in Hospitality \& Tourism, Vol. 11, No. 2, pp. 93-1 10.

5. Kjaerheim, K., Mykletun, R., Haldorsen, T. (1996), "Selection into the restaurant business based on personality characteristics and the risk of heavy drinking", Personality and Individual Differences, Vol. 21, No. 4, pp. 625-629.

6. Kwok, L., YU, B. (2013), "Spreading social media messages on Facebook: An analysis of restaurant business-to-consumer communications", Cornell Hospitality Quarterly, Vol. 54, No. 1, pp. 84-94.

7. Mihaylov, M. (2014), Sustainable development of tourism, New Bulgarian University, Sofia, pp. 17-25.

8. Revell, A., Blackburn, R. (2007), "The business case for sustainability? An examination of small firms in the UK's construction and restaurant sectors", Business strategy and the environment, Vol. 16, No. 6, pp. 404-420.

9. State Gazzete of Bulgaria (2016), Tourism Act, available at: http://dv.parliament.bg/DVWeb/broeveList.faces (08 July 2018) 


\section{About the authors}

Olga Alinova Mancheva-Ali is an assistant professor at the Department of Tourism, Faculty of Economics at St. Cyril and St. Methodius University of Veliko Tarnovo, Bulgaria. At present she is a PhD student at the Institute for Research and Innovation, Vasil Levski National Military University, Veliko Tarnovo in the field of non-material production management. Her research interests are in the fields of tourism, hospitality, specialized software and sustainable development in tourism. The author can be contacted at o.mancheva@uni-vt.bg.

Iliyan Nikolaev Lilov is a Full Professor at Department of Resource and Technology Managemen, Vasil Levski National Military University, Veliko Tarnovo, where he gained his PhD in Automatic in the field of Electronic computing. He also holds a Bachelor's degree in Finance and Master's Degree in ICE Engineer. He is a consultant for project BG05M2OP001-2.009-0001-C01. He has participated in many international scientific conferences. The author can be contacted at inid@nvu.bg. 